\title{
Conflicto Iglesia-Estado por el establecimiento de escuelas parroquiales en El Salvador (I89|-1893)
}

Roberto Armando Valdés Valle Departamento de Filosofía, UCA El Salvador

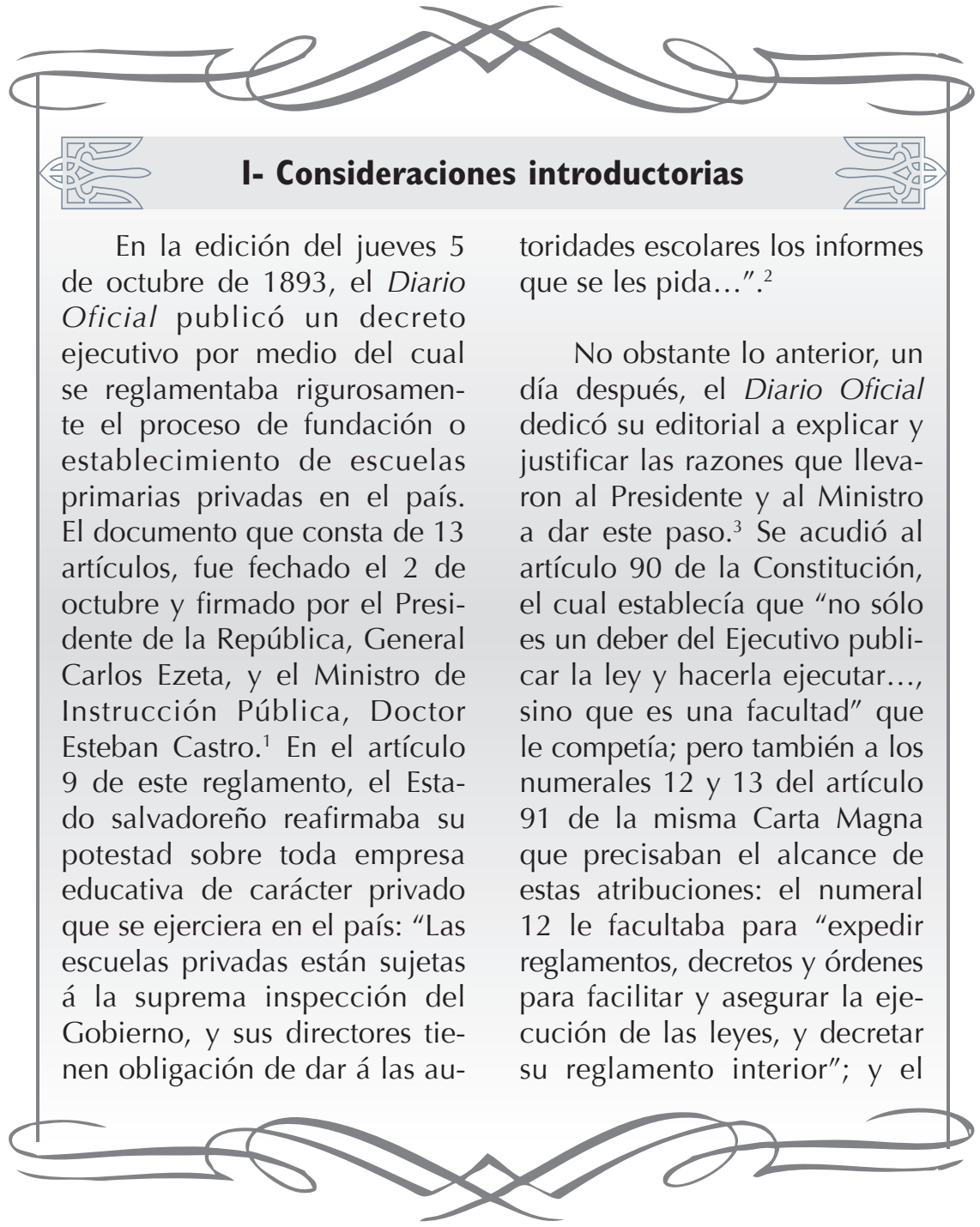


numeral 13 hablaba de "fomentar la instrucción pública en todos los ramos del saber humano, decretando estatutos y adoptando métodos adecuados". Si se daba el caso de que alguien se atreviera a argumentar -tal vez el Obispo salvadoreño Antonio Adolfo Pérez y Aguilar- que estas nuevas disposiciones contradecían lo estipulado en el artículo 33 de la Constitución de 1886 que establecía que la enseñanza en la República era libre (pero la primaria, obligatoria), el editorialista se adelantó a contra-argumentar en los siguientes términos:

... naturalmente para que se cumpla con esa prescripción, es necesario é indispensable que el Poder Ejecutivo tenga la suprema inspección, pues de otro modo no podría tener conocimiento exacto de si se cumple ó no con aquella disposición. Así el Ejecutivo, no sólo tiene la facultad sinó el deber de vigilar la enseñanza primaria, dictando leyes y reglamentos adecuados. ${ }^{4}$

Pero había una razón adicional, quizá la más decisiva, por la que el Estado salvadoreño finalmente se decidía a reglamentar el proceso de fundación de este tipo de escuelas. A juicio del redactor, "este decreto ha sido motivado por los informes que publicamos en nuestro número correspondiente al treinta del próximo anterior de setiembre"; $;$ y en efecto, en la edición de ese día, se publicaron los informes de los inspectores de educación de los Departamentos de San Vicente y San
Salvador, quienes realizaron una visita y evaluaron las escuelas católicas o parroquiales de varones que habían sido establecidas en estas ciudades desde inicios del año lectivo. ${ }^{6}$ Los resultados de la inspección ciertamente eran muy desfavorables para ambos centros escolares. Así, por ejemplo, el inspector de San Salvador, S. M. Noriega, en carta adjunta al informe enviado al Director General de Instrucción Primaria, el colombiano Francisco Gamboa, concluía lo siguiente:

A este propósito haré constar que á mi juicio, la existencia del mencionado plantel es nociva á la marcha general de la enseñanza, por las teorías que en él se inculcan á la juventud; así como también que debe ser sujetado á una vigilancia perpetua y rigurosa, á fin de que cause los menores daños posibles. ${ }^{7}$

Y el Inspector de San Vicente, Rafael Castillo, también en carta adjunta al informe enviado directamente al Ministro de Instrucción Pública, destacó otros aspectos negativos observados durante la visita. Entre ellos, se cuestionó la idoneidad moral de los encargados de la escuela: 
No creo demás manifestar á U. que los actuales maestros de dicha escuela, examinaron á mi presencia todas las clases y que durante dicho examen noté especialmente que el Director y 1er. Subdirector lo hacían con el cigarro en la boca. Además dichos sujetos no observan en esta sociedad una conducta satisfactoria. ${ }^{8}$

Al momento de presentar la Memoria de Labores de 1893 del Ministerio de Instrucción Pública, el doctor Esteban Castro también hizo un resumen de las razones que llevaron al Gobierno a decretar este reglamento, y rechazó de manera enfática que el objetivo primario haya sido clausurar las escuelas parroquiales, como habían esgrimido a lo largo del año los católicos:

Convencido el gobierno, por los informes frecuentes de los inspectores de Educación, de los señores gobernadores, presidentes de las juntas departamentales, y de muchos particulares de honorabilidad conocida, del pésimo servicio y mal estado de la mayor parte de las escuelas privadas y de los malos resultados que daban en los exámenes, se vio en el caso de poner término á tan grave mal, promulgando el decreto de 2 de octubre... No ha faltado quien diga que al emitir dicho decreto el Gobierno tuvo en mira únicamente cerrar las escuelas católicas y que dicha disposición es inconstitucional, porque restringe la libertad de enseñanza. No es racional atribuir fines cortos y estrechos á disposiciones que están fundadas en principios de alto alcance y de incalculable trascendencia social. ${ }^{9}$

No obstante las declaraciones del Ministro, el presente ensayo tratará de mostrar que tanto la promulgación del nuevo reglamento de creación de escuelas privadas, como la elaboración de estos informes citados deben al menos entenderse dentro de la dinámica de confrontación que persistía entre el Estado salvadoreño y de una Iglesia católica que se negaba a aceptar que la educación primaria en el país tuviera un carácter laico, como lo había establecido desde hacía ya 10 años la Constitución de 1883 y había sido ratificado por las Constituciones de 1885 y 1886. En el presente trabajo, voy a examinar la respuesta del semanario El Católico a las acusaciones vertidas por ambos inspectores, y al mismo tiempo se hará un esfuerzo por contextualizar el surgimiento de las escuelas parroquiales en el país, así como el contexto centroamericano en el que se dio este conflicto entre Iglesia y Estado. 


\title{
II- Origen de las escuelas parroquiales en
El Salvador en el contexto centroamericano
}

Como ha podido comprobar Olga Vásquez, la necesidad de crear escuelas parroquiales se propuso por primera vez por el Obispo Luis Cárcamo y Rodríguez en carta circular a los sacerdotes de la Diócesis fechada en agosto de 1880, en el contexto de la aparición de la denominada "Circular Ripalda" que ordenaba suprimir en las escuelas del Estado la enseñanza del catecismo de Jerónimo Ripalda. ${ }^{10}$ En lo tocante al tema que estamos abordando, el Obispo señaló lo siguiente:

\begin{abstract}
Art. 2. Procurarán con igual solicitud, cada uno según las circunstancias de sus respectivas parroquias, la fundación de escuelas parroquiales, o al menos, harán que los maestros y maestras de escuelas particulares enseñen convenientemente la doctrina a sus alumnos. ${ }^{11}$
\end{abstract}

La eliminación del catecismo de Ripalda tuvo lugar justo al iniciar el segundo período presidencial de Rafael Zaldívar (1880-1884), y anunciaba que se estaba a punto de re-tomar el proyecto de reformas radical-secularizantes impulsadas durante la Administración de Santiago González (1871-1876), proyecto del que formaba parte esencial la secularización de la escuela y la creación de un nuevo ciudadano laico que sustituyera al ya anacrónico y reaccionario ciudadano católico. ${ }^{12}$ Sin embargo, todo parece indicar que la propuesta de Cárcamo no prosperó en ese momento. Hubo que esperar más de una década para que el nuevo Obispo, Antonio Adolfo Pérez y Aguilar, en Carta Pastoral del 19 de diciembre de 1891, retomara con nuevos brillos el proyecto. ${ }^{13} \mathrm{El}$ documento inicia con la siguiente afirmación: "La educación religiosa de la niñez es una de las necesidades más graves y urgentes de nuestra diócesis"; y un poco más adelante precisa que tal urgencia es debido a que "por las leyes del Estado, se ha suprimido del programa de las escuelas públicas la enseñanza de la Religión, y se ha prohibido severamente á los maestros dar aun en privado, respecto de ella, noción alguna". ${ }^{14}$

Así, pues, ante la imposibilidad, de transformar el carácter laico de la educación estatal en el país, luego de la aprobación de la Constitución de 1886, y por ende dado el grave peligro en que se había colocado el destino último (la vida eterna) de la niñez salvadoreña por la ausencia de instrucción religiosa, el Obispo discurre sobre una solución ensayada en algunos países en los que igualmente se había imprimido a la educación primaria el carácter laico: crear escuelas parroquiales. 
Uno de estos medios, ventajosamente ensayados en países que, como Francia, Bélgica, los Estados Unidos del Norte, etc., están sometidos al mismo régimen de enseñanza oficial que nosotros, es la creación de escuelas católicas llamadas libres..., las cuales, colocadas al frente de las escuelas del Estado y quizá con el mismo programa de clases, pero con un espíritu de sana y verdadera instrucción, ofrecen á sus alumnos, en punto á Religión y moral cristiana, los conocimientos necesarios para el grado de cultura que exigen su propia perfección y dirección acertada y prudente en las diversas eventualidades de la vida, y su carácter esencialmente social en el seno de la patria y del hogar doméstico.

El Obispo destaca entonces que la Constitución de la República "sanciona en absoluto el principio de libertad de enseñanza", por lo que no encontraba motivos para que el Supremo Gobierno les negara el derecho de abrir tales escuelas. No se debe olvidar que unos 10 años antes, en 1881, el entonces Presbítero Pérez y Aguilar había logrado que el Estado salvadoreño, presidido por Rafael Zaldívar, reconociera la legitimidad de fundar Colegios católicos de segunda enseñanza en el país, amparado precisamente en el artículo de la Constitución que garantizaba la libertad de enseñanza. No había, pues, en principio razón para que en esta ocasión las cosas fueran distintas:

Las leyes del Estado no se oponen á ello. La constitución sanciona en absoluto el principio de libertad de enseñanza, y si reconoce ese precioso derecho á todo el que desee hacer uso de él, sea quien fuere, un particular, una corporación laica, una secta religiosa etc., no estaría dispuesta á negarlo á la Iglesia que lo tiene recibido de Jesucristo desde su fundación; que tiene la especial misión de salvar á los hombres por medio de la enseñanza, y que la ha practicado durante todos los siglos cristianos, sin interrupción alguna y con verdadera autoridad doctrinaria. ${ }^{15}$

En un breve comentario, el semanario El Católico saludó la iniciativa y añadió que el Obispo, "acompañado de una Junta de sacerdotes", había dado los primeros pasos para fundar las escuelas y se esperaba que en breve se dieran a conocer "los reglamentos y disposiciones concretas sobre este importante asunto".$^{16}$ Sin embargo, habrá que esperar -como veremos- al Primer Sínodo Diocesano salvadoreño, realizado en el mes de Noviembre del 92, para que se tomen medidas 
efectivas para impulsar este nuevo proyecto educativo. Mientras tanto, El Católico reprodujo un par de comentarios elogiosos a la Pastoral, que había sido publicada tanto por El Eco Católico de San José, Costa Rica, ${ }_{17}$ como por El Sentimiento Religioso de León, Nicaragua. ${ }^{18}$ Pero a decir verdad, la Pastoral del Obispo salvadoreño había sido precedida por otra escrita por el Obispo de Costa Rica, Bernardo Augusto Thiel, fechada el 4 de octubre de 1891, es decir dos meses y medio antes que la del prelado salvadoreño. ${ }^{19}$ En la introducción a su carta, el Obispo Thiel planteaba lo que él denominaba "la cuestión escuela" en los siguientes términos:

Entre las diferentes cuestiones que ocupan los ánimos en nuestra República sobresale en primer lugar la de la educación de la juventud y por consiguiente la cuestión "escuela", por cuanto éste es el medio principal de la educación. La cuestión "escuela" divide los espíritus en dos grupos: los católicos, que quieren la escuela católica, y los liberales que quieren la escuela laica. ${ }^{20}$

La referencia al estado de la problemática educativa en Costa Rica es relevante para el presente estudio, pues demuestra que las conquistas del liberalismo secularizante seguían sin estar escritas en piedra, y por ende cabía la posibilidad de que se dieran importantes cambios o retrocesos, como de hecho sucedió en Costa Rica en 1892, luego de 6 años de haberse instaurado la enseñanza laica. En efecto, a lo largo de 1892, El Católico mantuvo informado a sus lectores de los cambios que en política educativa venía introduciendo el gobierno del Presidente José Joaquín Rodríguez (1890-1894), ${ }^{21}$ quien, finalmente, con decreto ejecutivo fechado el 4 de agosto de 1892, restableció "en las escuelas primarias del Estado la enseñanza del Catecismo Cristiano y de la Historia Sagrada, impartida por los respectivos maestros, con la extensión que en el reglamento, textos y programas le dé la Secretaria de Instrucción Pública, previo informe de la Autoridad eclesiástica". ${ }^{22}$ De más está decir que El Católico y otros medios impresos ultramontanos celebraron por los aires este triunfo de la Iglesia sobre los Liberales secularizantes y pro-masónicos que habían dominado el escenario político de Centro América desde los tiempos de Justo Rufino Barrios (1873-1885); y era difícil no soñar o desear que algo similar a lo sucedido en Costa Rica ocurriera en El Salvador, si se llegara a dar un cambio importante en las altas esferas gubernamentales: 
Ya dos repúblicas de Centro-América, Nicaragua y Costa Rica, han logrado romper la cadena ignominiosa con que la masonería, por la mano déspota de Rufino Barrios, esclavizó los derechos y libertades de los centroamericanos. Ojalá que las otras tres, irguiendo noblemente sus cuellos y sacudidas por las palpitaciones de su autonomía, arrojen de sí esta argolla de la enseñanza laica, vergonzoso recuerdo de su degradante humillación al panterismo guatemalteco. ${ }^{23}$

La alusión a la situación en Nicaragua, sin embargo, también es relevante, pero en el sentido contrario, porque si bien es cierto que el gobierno de Roberto Sacasa (1889-1893) se mostraba partidario de la enseñanza católica, lo que lo hacía digno de las mayores alabanzas por parte del clero y la prensa católica de aquél país y en realidad de toda la región, ${ }^{24}$ con la llegada de José Santos Zelaya al poder (1893-1909), se impulsó el laicismo. De hecho, una vez instalado el nuevo Congreso Constituyente nicaragüense en 1893, los medios impresos ultramontanos no dudaron en afirmar que la mayoría de los Representantes electos eran de tendencia secularizante cuando no abiertamente masones:

El partido liberal, tan opuesto en sus principios y en sus tendencias á la Iglesia Católica, ha obtenido mayoría en el Congreso Constituyente que está elaborando el Código Fundamental de aquella República. Uno de sus primeros actos ha sido suprimir la Religión oficial de aquel pueblo católico en su totalidad, y dar la libertad de cultos sin estar establecido ninguno diferente del Católico en su territorio. Este contrasentido ha causado justa indignación en el pueblo nicaragüense, indignación que ha manifestado por varias protestas publicadas por la prensa. ${ }^{25}$

En un amplio estudio sobre la historia de la educación en Costa Rica, Iván Molina señala que, en efecto, el Presidente Rodríguez mostró una postura mucho más crítica respecto de la reforma educativa impulsada por las administraciones secularizantes de Próspero Fernández (1882-1885) y de Bernardo Soto (1885-1890), y que llevaron en
1886 a proclamar la laicización de la enseñanza primaria. A juicio de Molina, las estadísticas educativas muestran que a raíz de la reforma se había experimentado una importante caída en los niveles de matrícula en las escuelas oficiales, y la razón no parecía ser otra que la imposición de la educación laica: 
... la matrícula [en las escuelas del Estado] aumentó hasta 1886, empezó a disminuir en 1887, y se derrumbó en 1888 y 1889. Así pues, la oposición a la reforma se intensificó en dos años que coincidieron con la aprobación del matrimonio y el divorcio por lo civil (1888) y con el inicio de la campaña electoral de 1889. En ambos casos, la Iglesia católica jugó un papel central, tanto al adversar la secularización de la familia, como al apoyar a la oposición en la lucha electoral... Tras el triunfo de la oposición en 1889 y la llegada de Rodríguez a la presidencia en 1890, en junio de este año se emitió un decreto que estableció que los días sábados, de 11 de la mañana a dos de la tarde, serían suspendidas las lecciones regulares con el fin de que los niños y las niñas, de los padres que así lo desearan, pudieran recibir instrucción religiosa, la cual fue, por tanto, restablecida, aunque con un carácter voluntario. Además, a partir de 1890 -si no desde antes- parece que disminuyó la coacción de las autoridades sobre los padres de familia para que enviaran a sus hijos a la escuela.

\section{SIII- El Primer Sínodo Salvadoreño y el establecimiento de las primeras escuelas parroquiales}

Como ya se insinuó, la iniciativa del Obispo salvadoreño de fundar escuelas parroquiales no pasó de ser eso, una mera iniciativa, pues a lo largo de todo el año 92, El Católico hizo casi ninguna alusión al proceso de creación de estas escuelas; la atención en materia educativa estaba fijada en los importantes cambios que se estaban experimentando en Costa Rica. De ahí que tendremos que esperar hasta la realización del Primer Sínodo Diocesano para que el proyecto sea retomado. Es muy probable que el triunfo católico en Costa Rica haya estimulado al clero salvadoreño a revivirlo. El Sínodo fue convocado mediante Edicto episcopal el 29 de septiembre de 1892, y fijó la realización del mismo para los días 24 a 26 de noviembre. ${ }^{27}$

Al comentar El Católico el Edicto de convocatoria, alabó la decisión del Obispo, pues "las consideraciones que sirven de fundamento á dicha disposición, prueban palmariamente la importancia y necesidad de esas reuniones del clero, tan recomendadas por la Iglesia y tan frecuentes en los Obispados bien constituidos", y añadió que "las diócesis de CostaRica y de Honduras han tenido ya sus synodos y han reportado de ellos incalculables ventajas". ${ }^{28}$ Sin embargo, ni en las "consideracio- 
nes" esgrimidas por el Obispo en el Edicto para convocar al Sínodo, ni El Católico hizo alusión directa a la problemática de la educación laica ni a la propuesta de crear escuelas parroquiales, y lo mismo ocurrió con un breve comentario publicado en su edición del 13 de noviembre. Una vez concluido el Sínodo, El
Católico reseñó y comenzó a revelar los principales resultados del mismo. En uno de los textos refirió los siguientes datos que denotan efectivamente que los temas de la secularización (matrimonio civil y educación laica) no fueron ajenos a los padres sinodales:

Después de las preces con que la Iglesia implora las luces del Espíritu Santo, se leyó en dichas sesiones el proyecto de constituciones synodales, que contiene cerca de doscientos decretos ó artículos. Además, los informes de las comisiones y los proyectos de decretos y de reglamentos sobre instrucción acerca de matrimonios, sobre el Manual del Arzobispado, sobre Reglamentos para Círculos Católicos, para Cofradías en General, para la Cofradía de Doctrina Cristiana, para las Escuelas católicas, \& \& \&. ${ }^{29}$

Y en su edición del 4 de diciembre, El Católico reveló las temáticas de los decretos que fueron discutidos durante la segunda sesión del Sínodo, es decir el lunes 25 de noviembre:

La primera parte [de los decretos] relativa á la fé católica, consta de seis capítulos, á saber: De la profesión de fé; de la predicación de la divina palabra; de la enseñanza de la doctrina cristiana; de las escuelas católicas; de la masonería y demás sectas condenadas por la Iglesia; de los libros y periódicos. Todo lo relativo á estas importantes materias, concernientes al don inestimable de la fé, está reducido en treinta y un artículos ó decretos. ${ }^{30}$

En la siguiente edición, El Católico dio un paso más y sostuvo que "una de las disposiciones más importantes del Synodo Diocesano es la del establecimiento en la Parroquias de escuelas católicas, en que los niños aprendan teórica y prácticamente la religión que profesan", y añadió que "un hombre sin religión es siempre arrastrado por sus propias pasiones á toda clase de vicios". ${ }^{31}$ Por ello, el Obispo y el "V. Cabildo Eclesiástico" habían decidido abrir una escuela "á principios del año entrante, en el piso bajo de la casa de la Catedral... que por su posición central y por el número y amplitud de sus piezas, 
es muy aparente para escuela". Se le iba a denominar "Escuela del Divino Salvador". ${ }^{32}$ En consonancia con las anteriores resoluciones, para el día 9 de diciembre, el Obispo convocó a una reunión "en la casa episcopal, con el objeto de arreglar las bases de una escuela católica, que se desea fundar en esta capital á principios del años entrante". Según El Católico, a esta reunión asistieron "un número considerable de invitados, sin contar con los Sacerdotes", quienes, luego de que el mismo Obispo les informara "acerca de las bases principales del proyecto", las aceptaron "con entusiasmo y manifestaron la mejor voluntad en su favor". A continuación, se procedió a conformar una Junta Directiva, "para que, con la presidencia del Ilustrísimo señor Obispo y de un representante del Cabildo, discutiese sobre el reglamento de la escuela y sobre los medios de crearle fondos". La Junta Directiva quedó conformada de la siguiente manera: Presidente, el canónigo Miguel Vecchiotti; Vocal primero, Anselmo Valdés; Vocal segundo, Emeterio Ruano; Tesorero,
Ramón Rivas; y como Secretario, Fabio Castillo. Como suplentes, se nombró a Miguel Yúdice, a Juan María Villatoro, a Salvador Soler y a Belisario Calderón. ${ }^{33}$

Entre otras disposiciones, se estipuló que "dicho establecimiento debe ser dirigido por un Sacerdote que vivirá en la casa y se ocupará exclusivamente de la Escuela. Además dará las clases de religión y acompañará á los alumnos en los actos religiosos que practique". Pero El Católico tuvo el cuidado de añadir -sin duda para evitar alguna objeción de las autoridades educativas- que "seis profesores competentes ejercerán el magisterio en las asignaturas designadas en el plan oficial de estudios para las escuelas primarias, medias y supremas". ${ }^{34}$ Entonces, se procedió a la recolección de los fondos necesarios para su fundación y mantenimiento, pues era imperativo que la escuela -al igual que las oficiales- fuese gratuita, como señaló una circular enviada por la Junta Directiva a los posibles futuros patrocinadores:

Se trabaja con todo empeño por establecer una escuela primaria y gratuita, donde se dé la enseñanza en seis grados, prescrita por el Reglamento oficial del ramo, y en cuya escuela se dará también la más completa educación é instrucción católicas. Como la enseñanza se dará gratis á cuantos niños concurran, se hace indispensable la creación de recursos para fundar y conservar el plantel; y por esto nos dirigimos á las personas á quienes creemos que simpatiza este proyecto, interesadas como juzgamos que deben estar en el positivo bien de la sociedad, para que se sirva 
expresar al pie de la presente excitativa, que suplicamos devuelvan al señor Presidente de la Junta, la contribución mensual que guste. ${ }^{35}$

Ahora bien, no debe perderse de vista que fue a esta escuela parroquial establecida en San Salvador con tanto cuidado y esmero a la que precisamente unos meses más tarde el inspector del Ministerio de Instrucción Pública, S. M. Noriega, consideró que su existencia era "nociva á la marcha general de la enseñanza, por las teorías que en él se inculcan á la juventud", y por ende debería ser sujetada "á una vigilancia perpetua y rigurosa, á fin de que cause los menores daños posibles" ${ }^{36} \mathrm{Y}$ por su parte, el inspector que visitó la escuela parroquial de San Vicente, Rafael Castillo, comentó, respecto a la forma de financiar estas escuelas, lo siguiente:

Uno de los miembros de la Junta Directiva de esta escuela me manifestó: que poca sería la duración de este establecimiento, pues muchas de las personas contribuyentes para su sostenimiento, ya no quieren pagar su cuota mensual, habiéndose pasado muchos alumnos á la escuela oficial según lo expreso á U. en mi informe. ${ }^{37}$

No he podido precisar cuántas de estas escuelas se llegaron a establecer a lo largo de la Diócesis durante el primer año, pero tomando como base los datos proporcionados por El Católico ${ }^{38}$ se puede afirmar lo siguiente: Además de las ya referidas ubicadas en San Salvador y en San Vicente, ${ }^{39}$ un informe de la Vicaría de San Miguel señaló que "durante el año 1,892, y los tres meses que han trascurrido de este año, se han sostenido en esta parroquia dos escuelas católicas". ${ }^{40}$ Además de ellas, existe evidencia de la fundación de otra en el municipio de Tonacatepeque, ${ }^{41}$ una en Sonsonate ${ }^{42}$ y otra en Santa Tecla. ${ }^{43}$ También El Católico informó a finales de octubre que el señor Gobernador del Departamento de Morazán se había opuesto a la creación de una escuela en la ciudad de Gotera:

Hemos visto una carta de Gotera en la que se dice que, habiendo el señor Cura procurando establecer su Escuela Parroquial, el señor Gobernador se lo impidió, asegurándole que trabajaría en vano, pues tenía instrucciones para suprimir dichas escuelas. Como hasta ahora la ley no prohíbe dichos establecimientos, ni se ha publicado decreto alguno 
que los suprima, creemos que ningún empleado puede legalmente impedirlos. ${ }^{44}$

Esta última referencia nos remite de nuevo al conflicto que al parecer se había establecido entre el Estado y la Iglesia por la fundación de estas escuelas parroquiales, pues ciertamente el Gobernador no tenía la autoridad legal para impedir su apertura, si la mencionada escuela se trató de fundar antes de aprobado el nuevo reglamento del 2 de octubre del 93, pero si se quiso establecer después de su aprobación, en ningún momento se estaba cometiendo un "abuso de autoridad", como afirmaba El Ca- tólico, pues el artículo 1 del reglamento establece con claridad que "Toda persona que quiera fundar un establecimiento de educación primaria deberá dirigir un memorial al Gobernador del departamento respectivo, en el que hará la solicitud del caso...", y en su artículo 7 establece más específicamente que "Los Gobernadores departamentales impedirán toda fundación que se intente sin sujeción á este decreto y cerrarán toda escuela ya establecida que continúe sin tomar en cuenta el inciso anterior" ${ }^{45}$

\section{IV- Disputa entre secularizantes y católicos respecto de las escuelas católicas parroquiales}

Podemos dividir esta disputa en dos grandes momentos: previo a la publicación del nuevo reglamento para el establecimiento de escuelas privadas, y posterior a su publicación. Voy a analizar por separado ambos momentos.

\section{Informes desfavorables respecto de las escuelas católicas previo a la publicación del reglamento.}

La primera noticia que se ha podido encontrar sobre este conflicto entre los inspectores del Ministerio de Instrucción Pública y las escuelas parroquiales durante el año de 1893, se dio a conocer por carta que Gonzalo de Córdova enviara a El Católico a finales de febrero para quejarse del informe que el inspector del Departamento de San Vicente, el señor Castillo, había redactado casi recién establecida la escuela. ${ }^{46}$ De acuerdo con este despacho, la escuela había sido fundada el 8 de febrero, pero en el transcurso de 15 días, Castillo la había visitado en cinco ocasiones, "con el Reglamento en la mano, examinando, á cada uno de los profesores en el método de enseñar, leyendo, y exigiendo hasta la minuciosidad la lista de los objetos de que debía estar dotada". ${ }^{47} \mathrm{Al}$ parecer, Castillo atacó por primera vez las cualificaciones morales del Director, quien -a juicio del inspector- exhibía una "conducta notoriamente viciada", 
pero también señaló que la escuela "carece del mobiliario que la enseñanza moderna exige", "que los grados no están distribuidos conforme al Reglamento"; en definitiva, "que no se cumple con la ley reglamentaria". No me es posible analizar en detalle los contra argumentos esgrimidos por el señor Córdova para responder a estas acusaciones del inspector Castillo. Por ello, me quiero referir a las causas profundas que a juicio de Córdova llevaron a Castillo a redactar un informe tan desfavorable para la escuela:

Debo comenzar por decir [asevera Córdova]: que es público y notorio en San Vicente, que antes de fundarse esta escuela, el Señor don Rafael Castillo... en varias ocasiones se expresó prevenidamente contra dicha escuela, hasta protestar que él la haría morir tan luego como naciera, lo que efectivamente hubiera conseguido ya, á no haber encontrado en nuestro actual Gobernador, un hombre de orden y cumplido con la ley. ${ }^{48}$

La carta de Córdova añade una copia del informe que la Junta de Educación de la ciudad de San Vicente envió al Gobernador del Departamento que, por supuesto, ofrecía una visión más positiva so- bre la marcha de la escuela. Pero me gustaría traer a colación la manera en que este informe da cuenta de la manera en que se combinaba la educación oficial con la religiosa:

Como su nombre, de "Escuelas Católicas", lo indica, en ellas se enseña la religión católica, después de atender, como es debido, á la enseñanza de las materias que prescribe el Reglamento de Escuelas vigente; de manera que podemos afirmar que los establecimientos de que se trata, se hallan garantizados por la Constitución, puesto que la enseñanza que se da en ellos es enteramente moral y encaminada á labrar la felicidad de los individuos, si es que esta se puede encontrar en este valle de miserias y pesadumbres. ${ }^{49}$

En el mes de junio, El Católico informó que los días 5, 6 y 7 de abril, se realizó una visita oficial a las escuelas católicas de San Salvador y de Tonacatepeque. De acuerdo con la nota, el informe que el Director General de Educación Pú- blica Primaria, Francisco Gamboa, envió al Ministro de Instrucción fue una vez más "muy desfavorable á esos establecimientos". ${ }^{50}$ En su defensa, El Católico argumentó que los principales puntos destacados en el documento fueron las significativas 
deficiencias en el inmobiliario "y demás elementos exigidos por el Reglamento de Educación Primaria", pero sobre todo se destaca la dramática caída de alumnos inscritos, que había pasado de 484, a inicios del año escolar, a solo 167. En su respuesta a estas críticas, El Católico insistió en que no iba a negar "la verdad de lo informado por el señor Director General"; pero se añade, que si hubiera expresado "la justa causa de aquella deficiencia (de alumnos) y de la falta de puntualidad en aquel día, como parece exigirlo la mayor exactitud del Informe, este no hubiera sido tan desfavorable á dichas escuelas católicas". En consecuencia, justificó esta merma en la asistencia a que la inspección se realizó el día posterior a la finalización de las vacaciones de Semana Santa, por lo que -se concluye- "El Señor Director hubiera encontrado la misma ó mayor falta de alumnos en los establecimientos oficiales y aun en los mejor establecidos, si hubiera escogido ese día para visitarlos". ${ }^{51}$

Durante los meses de septiembre a noviembre, El Católico publicó varias notas en las que se informaba sobre la realización de los exámenes en las escuelas católicas; ${ }^{52}$ e insistió incansablemente en los "frutos amargos de la enseñanza laica", ${ }^{53}$ y de cómo esa enseñanza venía siendo derrotada no sólo en Costa Rica, sino también en algunas partes de México ${ }^{54}$ y de Europa. ${ }^{55}$ De más está decir que todos los informes publicados por El Católico sobre las escuelas parroquiales salvadoreñas les eran muy favorables tanto a éstas como a los rendimientos obtenidos por los estudiantes durante la práctica de los exámenes, contrario a lo que posteriormente afirmó el Ministro en su Memoria de Labores de 1893; se informó además que el Gobernador del Departamento de Morazán se había opuesto a la apertura de una escuela en Gotera, como ya se adelantó; pero no fue hasta la edición del 15 de octubre que El Católico respondió a los informes elaborados por Castillo y Noriega y que dieron pie a la elaboración del nuevo reglamento de fundación de escuelas primarias. Es el siguiente punto que quisiera analizar ahora.

\section{Respuesta de El Católico a los informes de Noriega y Castillo y la publicación del nuevo reglamento.}

En su edición del 15 de octubre, El Católico publicó dos textos en los que se respondió a los informes de los inspectores en cuestión. En el primero, titulado "Vindicación", El Católico comentó el informe de Noriega sobre la escuela de San Salvador, y en el segundo, "Prevención", escrito por Ignacio Paz -Director de la escuela de San Vicente-, se responde al informe de Castillo. Voy a examinar con un poco de detalle ambas respuestas. 
Yendo, en primer lugar, a la respuesta de El Católico al informe de Noriega, se comienza afirmando que el Inspector "ha hecho una grave ofensa directamente á los encargados inmediatos de la Escuela Católica de esta capital, é indirectamente á la Autoridad Eclesiástica que sostiene dicho establecimiento ${ }^{\prime \prime}{ }^{56}$ pues si se recuerda una vez más, Noriega había concluido que "la existencia del mencionado plantel es nociva á la marcha general de la enseñanza, por las teorías que en él se inculcan á la juventud". ${ }^{57} \mathrm{El}$ Católico demandó de Noriega ser más específico sobre cuáles eran las teorías nocivas que se inculcaban a los alumnos en la escuela:

Hacemos constar á nuestra vez, que lo que se enseña en dicha Escuela Católica es, ni más ni menos, las mismas asignaturas enseñadas en las escuelas públicas; solo se agrega el estudio de la religión católica, apostólica, romana, profesada por los alumnos y por sus familias. Si este estudio de la religión católica es las teorías que en dicha escuela se inculcan á la juventud, á que se refiere el Señor Noriega y que a su juicio, hacen que la existencia de dicho plantel sea nociva a la marcha general de la enseñanza, debió expresarlo claramente; para que sus frases abstractas no dieran lugar, como lo dan en realidad, á suponer que en dicha escuela se enseñan errores ó vicios nocivos á la sociedad. ${ }^{58}$

Y respecto a su recomendación de que la escuela se le sujetara "á una vigilancia perpetua y rigurosa...", El Católico respondió que "á tal vigilancia se sujetan solamente los estancos, casas de juego, tabernas, lugares de prostitución... etc., etc., á las cuales, según el juicio del Señor Noriega, debe equipararse la Escuela Católica". ${ }^{59}$ En efecto, al describir el horario de las clases, Noriega destacó que las clases de religión se ofrecían después de con- cluidas las oficiales. Así el horario regular era de "8 á 11 a.m. y de 1 á 4 p.m., dedicándose una, después de las señaladas, para la instrucción religiosa, lo que, como es evidente, debe fatigar demasiado á los concurrentes" ${ }^{60}$ Este último comentario incomodó nuevamente a El Católico y lo llevó a concluir que en realidad lo que se buscaba -sin declararlo abiertamente- era la eliminación definitiva de la enseñanza religiosa en estas escuelas:

Por lo visto, la instrucción religiosa es censurable á cualquier hora que se dé, para los partidarios de la instrucción laica. Hace poco que "El Eco Nacional" censuró, que en una escuela se enseñase la religión simultaneamente con 
las otras asignaturas, porque, decía, se pierde el tiempo que debe emplearse en estas: ahora el señor Noriega critica que se enseñe después, porque se fatigan los concurrentes; si se da la enseñanza religiosa antes que las otras clases, no faltará quién diga que se prefiere y antepone la religión á las ciencias. Con que ¿qué hacer? lo mejor es suprimir la clase de religión, según ellos, por no haber tiempo oportuno para ella. ${ }^{61}$

En cuanto al informe de la Escuela Católica de San Vicente, la respuesta de su director, Ignacio Paz, fue más breve, pero igualmente volvió a insistir en la parcialidad con la que había sido redactado, sobre todo al cuestionar la integridad personal del Director, como al parecer ya lo había hecho en el primer informe, y los problemas de presupuesto que enfrentaba:

Qué quiere decir esto? Que Castillo tiene prevención contra la pobre escuela: que no procede con justicia en su informe. El ha buscado todo cuanto desfavorable ha podido hallar, aunque de ninguna significación; y ha omitido lo favorable. Solo quisiera que Castillo dijera su parecer respecto del adelanto que en la escuela ha notado, y lo reto para que, ya que los exámenes están para darse, venga él mismo á replicar. Por hoy pongo fin, diciendo á Castillo que el Ministerio respectivo le ordenó practicase una (visita) Inspección en la escuela católica, y no en la vida privada de sus directores; pero respecto de lo que de conductas habla, apelo á la misma sociedad de San Vicente, para que diga si la de dicho Castillo es más satisfactoria que la mía, ó si él ha dado escándalos que jamás se me han achacado á mi. ${ }^{62}$

En su edición del 22 de octubre, El Católico dedicó su editorial de primera plana a abordar nuevamente el tema de estos informes, pero en esta ocasión añadió otro de sus temas preferidos y más recurren- tes: la Masonería. En efecto, en el primer párrafo del editorial acusó a masones y liberales de haberse confabulado una vez más para atacar a la Iglesia católica y desprestigiar a las escuelas católicas:

Por más que el liberalismo y la masonería acusen al Clero católico de enemigo de la instrucción y de las ciencias, la experiencia y los hechos, que valen más que las palabras, prueban que la Iglesia Católica es esencialmente docente, 
y que su sacerdocio tiende por naturaleza intrínseca, á difundir siempre y en todas partes la verdad y el bien... Pero desgraciadamente, el solo anuncio de ellas lla fundación de las escuelas católicas] despertó la rivalidad de algunos empleados de Instrucción Pública, que hacen de ella una explotación vergonzosa; su solo anuncio exaltó á la prensa, que vió en ellas nada menos que síntomas de futuras revoluciones y cediciones; su solo anuncio despertó en la masonería y masones del Salvador sus maquinaciones latentes contra la Iglesia. ${ }^{63}$

Nuevamente se recurrió a supuestas acciones de los masones en contra de las escuelas católicas, luego de que el Ministro de Instrucción Pública, Esteban Castro, junto con un doctor mexicano de apellido Revueltas (supuestamente miembro de la masonería mexicana), visitaran el hospicio y la escuela anexa que dirigían las Hermanas de la Caridad en San Salvador. De acuerdo con El Católico, luego de la inspección de ambos, había corrido el rumor de que se pensaba revocar el contrato que tenían las Hermanas con el Gobierno para administrar ambos establecimientos:

De aquí la multitud de interpretaciones y de comentarios que se hacen de la visita del señor Ministro, de sus iniciativas y más aún de la revisión de las bases de la contrata. Estas alarmas crecen y aumenta tanto más, cuanto que, dicen, haberse trascendido que el Doctor Revueltas, tanto por su filiación masónica como por sus ideas liberales, no tiene muchas simpatías por las Hermanas de la Caridad y por sus establecimientos, que fueron expulsadas y cerrados en México. ${ }^{64}$

Aunque todo parece indicar que no se llegó a revocar el contrato que existía con las religiosas, y no se ha podido obtener más detalles sobre la visita del tal Doctor Revueltas y su supuesta filiación masónica, sí existe evidencia de que Esteban Castro, el Ministro de Instrucción Pública, fue miembro de la masonería salvadoreña, pero no he podido precisar desde cuán- do. ${ }^{65}$ Además de ellos, el mismo Presidente, Carlos Ezeta, ${ }^{66}$ había pertenecido a la Masonería y lo mismo su Ministro de Gobernación, Domingo Jiménez. ${ }^{67}$ Por lo tanto, las referencias y ataques a la Masonería por parte de El Católico tenían algún fundamento en la realidad.

Para finalizar, digamos que de acuerdo con un "Remitido" publi- 
cado por El Católico -y firmado por "Los padres de familia"-, "el Supremo Gobierno, en uso de sus legítimas facultades y atento siempre al bienestar público, ántes de que empieze á regir el decreto de 2 de octubre, próximo pasado, como contrario á la libertad de enseñanza y anticonstitucional, piensa derogarlo" ${ }^{68}$ A esto debe decirse que la Memoria de Labores del Ministro de Instrucción Pública no da cuenta de que se haya decidido a derogar tal decreto; y por otro lado, nunca quedó claro en todas las argumentaciones esgrimidas por El Católico por qué el nuevo reglamento iba a imposibilitar efectivamente la creación de nuevas escuelas católicas, pues en ningún momento se estableció en él una prohibición explícita en contra de ellas, o contra la enseñanza de la religión católica, como lo señaló también la Memoria del Ministro. A lo sumo, El Católico llegó a afirmar que las disposiciones contenidas en el reglamento "difi- cultan mucho, por no decir imposibilitan en absoluto, la fundación y existencia de las escuelas católicas en la Diócesis del Salvador". ${ }^{69}$ ¿Es que estas escuelas realmente no podían cumplir con el reglamento en cuanto a los requerimientos de materiales pedagógicos, de condiciones físicas adecuadas o de maestros cualificados y reconocidos? Sin embargo, los católicos pedían se les tratara con justicia y se exigiera con igual insistencia el cumplimiento de todas estas condiciones tanto a las escuelas privadas como a las oficiales. ¿Qué pensar de todo esto? Quizá se podría concluir que el conflicto tenía unas raíces históricas más hondas y que tenían que ver no tanto con normativas particulares que buscaban reglamentar legítimamente las actividades educativas en el país, cuanto con concepciones ideológicas y políticas fuertemente antagónicas que se comenzaron a incubar luego del triunfo de los liberales radicales en 1871 .

\section{V- Algunas reflexiones finales}

Soy de la opinión que no debería menospreciarse estas constantes disputas entre liberales secularizantes y católicos después de la aprobación de la Constitución Política de 1886 que reafirmó el carácter laico del Estado salvadoreño. Estas escaramuzas prueban -a mi parecer- que los sectores opuestos a la secularización del país no habían perdido todavía la esperanza de que las cosas podían cambiar. Un buen ejemplo de esto sería precisamente esta discusión por la creación de las escuelas católicas, pero hubo otras escaramuzas, como los intentos fallidos porque la Asamblea Legislativa aprobará una ley de divorcio absoluto, revés para los liberales secularizantes que también fue celebrado con gran entusiasmo por El Católico. ${ }^{70}$

Lamentablemente para la historia de El Salvador, se ha perdido 
la mayoría de la rica y amplia producción periodística en la que se debatía sobre estos temas y poder así contrastar con mayor objetividad los argumentos esgrimidos por ambos bandos. Es de lamentar en especial la pérdida de la mayor parte de la producción de los intelectuales secularizantes, por lo que debo reconocer que el análisis de la controversia que se generó a raíz de la fundación de las escuelas católicas se ha fundado sobre todo en lo recogido por los sectores ultramontanos. Siendo consciente de estas graves limitaciones, se ha hecho un esfuerzo por mostrar que el conflicto efectivamente existió, y que la Iglesia no se dio por derrotada tan fácilmente, no después del triunfo que había representado los importantes cambios educativos realizados en Costa Rica por ese entonces.

Por suerte, se cuenta con extractos de las Memorias que el Secretario de Instrucción Pública presentó ante la Asamblea Legislativa durante los años que estamos examinando. Ellas nos permiten valorar la importancia que tuvo el establecimiento de estas escuelas parroquiales, más allá de las opiniones expresadas por El Católico. Así, en la Memoria del año 92, el Ministro se refirió más bien diríamos lacónicamente sobre las dificultades que esta Cartera de Estado había encontrado respecto de la Instrucción primaria, es decir, la que era gratuita, obligatoria y laica:

La asistencia de educandos fue mayor, no obstante haber funcionado menor número de escuelas y sin embargo de la propaganda que se ha hecho contra la enseñanza oficial, debido á la vigilancia que para el efecto han ejercido las autoridades. ${ }^{71}$

Como se puede apreciar, el Ministro da cuenta de la "propaganda que se ha hecho" contra las escuelas del Estado, pero no especifica quién la propalaba. Podemos aventurarnos a pensar que el Ministro estaba haciendo referencia a la Iglesia católica, y no sería descabellado hacerlo; pero también se aclara que la causa del malestar no estaba tanto por el carácter laico de la enseñanza, cuanto por la "vigilancia" que la Secretaría de Estado había comenzado a ejercer sobre las actividades desarrolladas por las escuelas; en consecuencia, podría pensarse también que las críticas provenían de los mismo directores o maestros que se sentían incómodos por esta inspección. Sin embargo, en la Memoria de Labores correspondiente al año 93, el Ministro se tomó un poco más de tiempo para explicitar los conflictos que se dieron en materia de instrucción primaria. Me voy a permitir transcribir parte de esta Memoria presentada a la Asamblea por el Doctor Esteban Castro: 
Desde que se estableció la enseñanza laica en las escuelas, el fanatismo religioso irguió la cabeza y dio principio á una propaganda activa contra las escuelas oficiales, desacreditándolas por todos los medios posibles, hasta por el vedado del púlpito y el confesionario. Esto ofreció una brillante oportunidad á los más ignorantes y aun á los viciosos para especular abriendo escuelas privadas en que ofrecían dar la enseñanza católica. Estas escuelas mal servidas y sin elementos, se llenaban de alumnos y hacían el vacío en las del Gobierno, aunque estas fueran verdaderos templos de completa educación. Bastaba que una escuela se llamara católica, que se cantara la Salve Regina y se enseñara el Ripalda, para que fueran despreciadas por muchos, las grandes conquistas de la Pedagogía moderna. ${ }^{72}$

Destaca en primer lugar, que en esta ocasión el Ministro dedicó en su Memoria un apartado especial al tema que venimos desarrollando, con el título, "Escuelas privadas". En segundo lugar, es notorio la manera que califica el espíritu de quienes promovieron la apertura de estas escuelas: "fanatismo religioso", y no duda en calificar a algunos de sus promotores como "ignorantes" y "viciosos", seguramente haciendo referencia al informe de Castillo sobre la vida personal del Director de la Escuela de San Vicente. Pero teniendo en cuenta que la iniciativa de fundar estas escuelas provino originalmente del Obispo, del Cabildo Eclesiástico y que fue apoyado decididamente por el Sínodo Diocesano, no cuesta mucho pensar que muy probablemente a juicio del Ministro el "fanatismo religioso" estaba francamente incrustado en la misma Jerarquía de la Iglesia salvadoreña. Si a esto le agregamos que de acuerdo con el Ministro "el Clero del Salvador, el más humilde é ilustrado de Centro-América, lejos de protestar contra el decreto, ha sido el primero en someterse á él", vendría a confirmar una vez más que para el Ministro El Católico orquestaba una batalla propia y no expresaba el sentir de la mayoría del clero salvadoreño.

Sin embargo, destaca el reconocimiento que hace el Doctor Castro de que estas escuelas católicas lograron reducir la asistencia de alumnos a las escuelas oficiales o del Estado. Se trata de una situación bastante parecida a la que Iván Molina describe en su estudio sobre la educación en Costa Rica, cuando demuestra que por estos mismos años se experimentó una importante reducción en la matrícula de las escuelas oficiales a causa de la educación laica que se impartía en ellas. En ese sentido, es interesante 
la manera en que Molina cuestiona la interpretación que la intelectuali-

dad liberal costarricense dio de esta reducción en la matrícula escolar:

La caída en la matrícula ocurrida a partir de 1887, que ha llevado a algunos autores a quejarse de la ignorancia de los padres acerca de las ventajas que la educación podía ofrecer a sus hijos no se ajusta obviamente a tal interpretación. La resistencia a enviar a los hijos a la escuela surgida de la reforma no fue motivada por la ignorancia, sino porque las familias populares estaban en desacuerdo con la reforma que les había sido impuesta... La evidencia que definitivamente refuta la teoría de la ignorancia popular es el dato de 1891, el cual demuestra que la sociedad costarricense, y en especial los sectores populares, habían reasumido su compromiso con la educación, una vez lograda la reintroducción de la enseñanza religiosa. En este último año, la proporción de niños y niñas de 7 a 12 años que asistían a la escuela había vuelto casi al nivel de 1883, y dos años después, esa proporción había aumentado en casi ocho puntos porcentuales. Dicho compromiso se manifestó, adicionalmente, en nuevas y mayores demandas por más escuelas y mobiliario. ${ }^{73}$

A este respecto, es también importante insistir, como lo ha hecho Iván Molina, en la necesidad de revalorizar la postura de los sectores conservadores y católicos que se resistieron a que sus hijos fuera educados en escuelas laicas; es necesario sobre todo remover el prejuicio de los liberales radicales de que las reservas se debían a la ignorancia promovida por la Iglesia católica y el clero, a los que se les describe como enemigos per se de la educación. En lugar de esta interpretación ideologizada, más bien habría que leer estas resistencias como una medida -diríamos ahora- de desobediencia civil ante la imposición de políticas educativas que resultaban inaceptables para una población claramente católica, que logró poner en apuros algunas de las iniciativas impulsadas por los gobiernos liberales secularizantes. 
Notas

1 "Ministerio de Instrucción Pública", Diario Oficial (231), jueves 5 de octubre de 1893 , p. 353.

2 Ibíd.

3 "Sección editorial", Diario Oficial (232), viernes 6 de octubre de 1893, p. 357.

4 Ibíd.

5 Ibíd.

6 Cfr. "Informe del Inspector de Educación de San Vicente, sobre la Escuela Católica de varones de aquella ciudad" e "Informe del Inspector de Educación de San Salvador, sobre la Escuela Católica de varones de esta ciudad", Diario Oficial (227), sábado 30 de setiembre de 1893, pp. 329-330.

7 "Informe del Inspector de Educación de San Salvador, sobre la Escuela Católica de varones de esta ciudad", Diario Oficial (227), sábado 30 de setiembre de 1893 , p. 329.

8 "Informe del Inspector de Educación de San Vicente, sobre la Escuela Católica de varones de aquella ciudad", Diario Oficial (227), sábado 30 de setiembre de 1893 , p. 329.

9 "Memoria de la Secretaría de Instrucción Pública y Beneficencia, presentada a la Honorable Asamblea Nacional el 8 de marzo de 1894, Diario Oficial (82), lunes 9 de abril de 1894, p. 420.

10 Para un desarrollo más completo de esta propuesta del Obispo Cárcamo y Rodríguez en el contexto de la promulgación de la "Circular Ripalda", puede consultarse el trabajo de Olga Carolina Vásquez Monzón El debate sobre la educación femenina en el contexto de la laicización del Estado salvadoreño (1871-1889), tesis de Doctorado en Filosofía Iberoamericana, Universidad Centroamericana
"José Simeón Cañas", El Salvador, septiembre de 2012, pp. 180-188. Disponible en http://www.uca.edu.sv/ filosofia/admin/files/1347991285.pdf

11 "Pastoral del M. I. Sr. Vicario Capitular del Salvador sobre la Educación Cristiana", El Católico (295), domingo 22 de mayo de 1887, p. 49.

12 Véase también Julián González Torres Del ciudadano católico al ciudadano laico. La escuela pública primaria y la formación de los futuros ciudadanos. El Salvador 1824-1890, tesis de Doctorado en Filosofía Iberoamericana, Universidad Centroamericana "José Simeón Cañas", El Salvador, junio 2012. Disponible en: http://www.uca.edu.sv/filosofia/ admin/files/1341957152.pdf

13 Antonio Adolfo Pérez y Aguilar, "Pastoral del Ilmo. y Rvmo. Señor Obispo diocesano sobre fundación de escuelas parroquiales", El Católico (499), 27 de diciembre de 1891, pp. 1-3. Este semanario se publicaba los domingos.

14 Ibíd., p. 2.

15 Ibíd.

16 "Pastoral", El Católico (498), 20 de diciembre de 1891, p. 4.

17 “Reproducción”, El Católico (506), 14 de febrero de 1892, p. 4.

18 "Precioso documento", El Católico (507), 21 de febrero de 1892, p. 8.

19 "Nos Bernardo Augusto Thiel...", El Católico (507), 21 de febrero de 1892, pp. 1-7.

20 Ibíd., p. 1.

21 Puede consultarse los siguientes comentarios: "Reproducción”, El Católico (506), 14 de febrero de 1892, pp. 4-5; "Buena armonía", El Católico (519), 22 de mayo de 1892, pp. 5-6; "Diócesis de CostaRica", El Católico (520), 29 de mayo de 1892, p. 7. 
"José J. Rodríguez, Presidente de la República de Costa Rica”, El Católico (538), 2 de octubre de 1892, p. 5.

23 "Restablecimiento de la enseñanza religiosa en las escuelas primarias oficiales de Costa-Rica”, El Católico (538), 2 de octubre de 1892, pp. 4-5. Puede consultarse también los siguientes comentarios y reproducciones sobre este cambio en la política educativa costarricense: "Diócesis de Nicaragua", El Católico (540), 16 de octubre de 1892, pp. 6-7; "Restablecimiento de la enseñanza religiosa en las escuelas primarias oficiales de Costa Rica", El Católico (541); 23 de octubre de 1892, pp. 2-4.

24 Puede consultarse los siguientes comentarios: "Buena armonía", El Católico (519), 22 de mayo de 1892, pp. 5-6; "Diócesis de Nicaragua", El Católico (525), 3 de julio de 1892, p. 5; "Diócesis de Nicaragua”, El Católico (528), 24 de julio de 1892, pp. 4-5.

25 "Diócesis de Nicaragua", El Católico (592), 10 de diciembre de 1893, pp. 7-8.

26 Iván Molina, "Educación y sociedad en Costa Rica: de 1821 al presente (una historia no autorizada), Diálogos: Revista electrónica de bistoria (2), 2007, pp. 206-207. Disponible en: http://www. historia.fcs.ucr.ac.cr/articulos/2007/ vol2/7vol8n2imolina.pdf

27 "Edicto Episcopal de convocación al Primer Synodo Diocesano del Obispado de San Salvador", El Católico (538), 2 de octubre de 1892, pp. 3-4.

28 "Edicto eclesiástico", El Católico (538), 2 de octubre de 1892, p. 6.

29 "Las sesiones privadas del Synodo diocesano", El Católico (546), 27 de noviembre de 1892, p. 4.
30 "El Synodo diocesano", El Católico (547), 4 de diciembre de 1892, p. 4.

31 "Escuela católica", El Católico (549), 18 de diciembre de 1892, p. 3.

32 "La Escuela Católica del Divino Salvador", El Católico (588), 12 de noviembre de 1893, pp. 3-4.

33 "Escuela católica", El Católico (549), 18 de diciembre de 1892, pp. 3-4.

34 Ibíd., p. 3.

35 Ibíd.

36 "Informe del Inspector de Educación de San Salvador, sobre la Escuela Católica de varones de esta ciudad", Diario Oficial (227), sábado 30 de setiembre de 1893 , p. 329.

37 "Informe del Inspector de Educación de San Vicente, sobre la Escuela Católica de varones de aquella ciudad", Diario Oficial (227), sábado 30 de setiembre de 1893, p. 329.

38 "Vindicación", El Católico (560), 3 de mayo de 1893, pp. 5-6.

39 "Las escuelas católicas", El Católico (571), 31 de mayo de 1893, p. 5.

40 "Vicaría de San Miguel", El Católico (567), 23 de abril de 1893, p. 5.

41 "El informe", El Católico (573), 4 de junio de 1893 , p. 7.

42 "Escuela católica de Sonsonate", El Católico (587), 5 de noviembre de 1893, p. 5 .

43 "La escuela de Santa Inés", El Católico (587), 5 de noviembre de 1893, p. 4.

44 "Abusos de autoridad", El Católico (586), 29 de octubre de 1893, p. 4.

45 "Ministerio de Instrucción Pública", Diario Oficial (231), jueves 5 de octubre de 1893, p. 353. 
46 "Vindicación", El Católico (560), 3 de mayo de 1893 , pp. 5-6.

47 Ibíd., p. 5.

48 Ibíd.

49 Ibíd. A finales de mayo, El Católico publicó una pequeña nota en la que da cuenta de la buena marcha de la escuela de San Vicente. Véase "Las escuelas católicas”, El Católico (571), 31 de mayo de 1893 , p. 5.

50 "El Informe", El Católico (573), 4 de junio de 1893 , p. 7.

51 Ibíd.

52 "Escuela católica de San Vicente", El Católico (578), 3 de setiembre de 1893, p. 4; "Escuelas católicas de San Miguel”, El Católico (581), 24 de setiembre de 1893, p. 5; "Objetos para la Escuela Católica de esta Ciudad", El Católico (585), 22 de octubre de 1893, pp. 2-3; "La escuela de Santa Inés", y "Escuela católica de Sonsonate", El Católico (587), 5 de noviembre de 1893, pp. 4, 5-6; "La Escuela Católica del Divino Salvador", El Católico (588), 12 de noviembre de 1893 , pp. 3-4.

53 "Frutos amargos de la enseñanza laica", El Católico (545), 20 de noviembre de 1892 , p. 5.

54 "Libertad de enseñanza", El Católico (586), 29 de octubre de 1893, pp. 2-3; "La enseñanza Laica y la Justicia", El Católico (587), 5 de noviembre de 1893, pp. 1-2.

55 "Enérgica protesta", El Católico (588), 12 de noviembre de 1893 , p. 5; "Derrota de la enseñanza laica", El Católico (590), 26 de noviembre de 1893, p. 6.

56 "Vindicación", El Católico (584), 15 de octubre de 1893, p. 4.

57 "Informe del Inspector de Educación de San Salvador, sobre la Escuela Cató- lica de varones de esta ciudad", Diario Oficial (227), sábado 30 de setiembre de 1893, p. 329.

58 “Vindicación”, El Católico (584), 15 de octubre de 1893, pp. 4-5. Cursivas en el original.

59 Ibíd., p. 5.

60 "Informe del Inspector de Educación de San Salvador, sobre la Escuela Católica de varones de esta ciudad", Diario Oficial (227), sábado 30 de setiembre de 1893, p. 329.

61 "Vindicación", El Católico (584), 15 de octubre de 1893 , p. 5. Para una ampliación de la argumentación de El Católico en contra de los argumentos de Noriega, puede consultarse el comentario "Réplica", El Católico (586), 29 de octubre de 1893, pp. 5-7.

62 Ignacio Paz, "Prevención", El Católico (584), 15 de octubre de 1893 , p. 6.

63 "Escuelas Católicas", El Católico (585), 22 de octubre de 1893, pp. 1, 2.

64 "Rumor", El Católico (585), 22 de octubre de 1893, p. 4.

65 No existe una ficha de Esteban Castro en el Archivo del Supremo Consejo Centro-Americano (ASCC G33) con sede en la ciudad de Guatemala, pero referencias a sus actividades masónicas durante las dos primeras décadas del siglo XX fueron recogidas por Francisco J. Ponte Domínguez en su Historia de la Masonería Salvadoreña, Sonsonate, Imprenta "Excélsior", 1962, pp. 64-65, $74-75,85$.

66 ASCC G33, "Carlos Ezeta”, Registro Masónico del Supremo Consejo CentroAmericano, $N^{\circ}$ 961, F. 215. Según esta ficha, Ezeta tenía 30 años al momento de ser admitido a la masonería, su estado civil era casado, era originario de San Salvador, donde también residía; 
era militar de profesión y su religión era la católica. Fue miembro de la Logia "Excélsior N ${ }^{\circ} 17$ ", en la que recibió el Grado 1 el 11 de diciembre de 1885, y el Grado 3, el 5 de enero de 1887. Sin embargo, se añade que fue expulsado de esta Logia el 31 de agosto de 1888, es decir dos años antes de llegar a la Presidencia (luego de derrocar a Francisco Menéndez). No obstante lo anterior, es imposible saber por ahora si Ezeta siguió siendo o no masón luego de esta expulsión.

67 ASCC G33, "Domingo Jiménez", Registro Masónico del Supremo Consejo Centro-Americano, No 937, F. 191. Según esta ficha, Jiménez tenía 36 años, era originario de San Salvador, donde también residía al momento de elaborarse la ficha. Era médico, su religión era la católica. Su Logia Madre era la "Excélsior $N^{\circ} 17$ ", en la que recibió el Grado 1 el 30 de agosto de 1882; el Grado 2 el 6 de junio de 1883, y el Grado 3, el 25 de enero de 1884. Por último señala la ficha que Jiménez fue expulsado de esta Logia el 31 de agosto de 1888, junto con Carlos Ezeta y otros masones.

68 "Estamos de plácemes", El Católico (594), 24 de diciembre de 1893, p. 6.

69 "Escuelas Católicas", El Católico (585), 22 de octubre de 1893 , p. 2.
70 Cfr. "Trigésima cuarta sesión de la Asamblea Nacional de la República, celebrada en San Salvador el día catorce de abril de mil ochocientos noventa y tres", Diario Oficial (95), martes 25 de abril de 1893 , p. 451 . Véase también, las reacciones de El Católico a esta decisión reiterada de los diputados salvadoreños: "El divorcio absoluto", El Católico (513), 2 de abril de 1892, pp. 3-4; "La ley del divorcio", El Católico (565), 9 de abril de 1893, pp. 1-3; "Alcance al número 565 de 'El Católico"” y "iHonor y gloria á la Asamblea Nacional!", El Católico (566), 16 de abril de 1893, pp. 3-4, 7. Los comentarios son inundatorios especialmente durante los meses de abril y mayo de 1893.

71 "Memoria de la Secretaría de Instrucción Pública y Beneficencia presentada a la H. Asamblea Nacional el 8 de marzo de 1893", Diario Oficial (71), jueves 23 de marzo de 1893, p. 322.

72 "Memoria de la Secretaría de Instrucción Pública y Beneficencia, presentada a la Honorable Asamblea Nacional el 8 de marzo de 1894, Diario Oficial (82), lunes 9 de abril de 1894, p. 420.

73 Iván Molina, "Educación y sociedad en Costa Rica: de 1821 al presente (una historia no autorizada), Diálogos: Revista electrónica de historia (2), 2007, pp. 207-208. 